\title{
O Direito Autoral e os Clubes Sociais no Brasil*.
}

\author{
Arnoldo Medeiros da Fonseca Junior \\ Consultor Jurídico da Associação de Clubes Sociais. \\ Consultor Especial junto a Comissão do Ministério da \\ Educacão e Cultura, na Biblioteca Nacional, para \\ estudos Legislativos de Direito Autoral.
}

Estamos na iminência de ver aflorar, a qualquer instante, em nossos horizontes jurídicos, pela primeira vez, um Código de Direitos do Autor e Direitos Conexos.

Seguindo esclarecida orientação, o Governo Federal resolveu dar unidade à extremamente dispersa e variada legislação existente.

Um Anteprojeto da autoria do preclaro Desembargador Mrtron Sebastião Barbosa foi publicado em 1967.

Dois outros projetos, substitutivos ao anterior, estão atualmente em mãos do sr. Ministro da Justiça para exame.

O primeiro é da mesma lavra daquele que já foi publicado com a coautoria ilustre do professor Antônio Chraves, (cuja presença, aliás, honra o nosso plenário);

$\mathrm{E}$ o segundo, da elaboração do não menos insigne Ministro CÂndido Motta FiLHo.

É nesta contingência, em que a Lei Nova está para surgir que mais importante se torna a análise e compreensão dos chamados Direitos Autorais, que tanto inquietam os clubes no Brasil.

* Conferência pronunciada por ocasião da $1 .^{a}$ Convenção Nacional dos Clizbes Sociais, em 25 de abril de 1973, em que o autor participou como assessor jurídico para problemas de Direito Autoral. 
Nossa exposição tentará resumir uma visão extremamente didática da matéria, atendo-se no decorrer ao chamado Direito de Execução Pública, para afinal sugerir medidas práticas que eliminem as dificuldades e os desajustes existentes.

Antes de começar, gostaria de lembrar um fato importante na futura consideração dos interesses dos Srs. Convencionais.

Desde 18291, no exterior, e de setembro de $1917^{2}$, no Brasil, estão os autores apropriadamente reunidos em sociedades constituídas para a arrecadação e defesa de seus direitos. Só agora, porém, praticamente 56 anos depois, é que os Clubes Sociais arquitetam formas amplas de organização para zelar unificadamente pelos seus interesses. $\mathrm{E}$ já era tempo que a isso se resolvessem. Pois as conseqüências daquela inação e isolamento, os Srs. podem e devem tentar avaliar.

O Estado procura sempre garantir aos indivíduos uma remuneração pelo seu trabalho. $O$ esforço intelectual e físico empregado por uma pessoa na criação de uma obra literária, artística ou científica merece igual compensação.

A coletividade tem o interesse fundamental em difundir, preservar e incentivar as criações do espírito, porque irão elas constituir, em seu conjunto, o patrimônio cultural de uma nação. E o desenvolvimento não se obtém sem a cultura.

A Constituição Federal em seu artigo 180 preceitua: " $O$ amparo à cultura é dever do Estado".

Não se trata, apenas, de compensar a atividade dinâmica representada pelo trabalho, mas é sobretudo o resultado obtido que empolga a ordem jurídica. $O$ produto da

1. Fundação da "Société des Auteurs et Compositeurs Dramatrques" - França.

2. Fundação da "Sociedade Brasileira de Autores Teatrais" "SBAT". 
atividade intelectual é tão importante, que gera direitos especiais para o seu criador.

A mesma Constituição no artigo 153, tratando dos direitos e garantias individuais, assegura: "Aos autores de obras literárias, artísticas ou científicas, pertence o direito exclusivo de utilizá-las. Esse Direito é transmissivel por herança pelo tempo que a lei fixar".

Esses os chamados Direito de Autor.

Internacionalmente, estão reconhecidos e assegurados pelo Brasil, através da ratificação e posterior promulgação das Convenções de Berna e sua revisão de Bruxelas, pela Convenção de Washington, e pela de Genebra.

A obra que resulta da criação intelectual, pode ser utilizada de várias formas. Sendo o autor o seu primeiro e principal crítico, pode evidentemente, melhor do que ninguém, julgar a conveniência ou não da utilização por qualquer meio ou processo, determinando, inclusive, a maneira pela qual esse uso deve ocorrer.

Assim, pode se evitar que na sua difusão sejam transfiguradas as características básicas de uma obra, desvirtuando-se desta forma a sua mensagem cultural, que é exatamente o que se deve preservar.

0 autor tem o maior interesse em que as emanações da sua intelectualidade sejam divulgadas com perfejção, por que sabe muito bem que as deficiências lhe serão indiretamente atribuídas, já que está vinculado pessoalmente à obra.

Com intenção de o estimular a contribuir para o patrimônio cultural do país, e como dupla compensação pela sua criatividade e vigilância é que do uso da obra por terceiros se fez derivar para ele o direito de receber remuneração ou requerer indenização nos casos em que a utilização se fizer sem o seu consentimento.

Os seus herdeiros são igualmente beneficiados, porque o relacionamento que mantêm com o autor faz presumir que tenham o mesmo desejo e interesse que a mensagem se 
difunda com precisão, e porque anima o criador a consciência de que com o seu trabalho poderá também garantí-los economicamente.

Assim a autoridade legítima emana normas de conduta, revestidas de suficiente coerção, para a composição dos conflitos de interesses existentes entre a coletividade e seu empenho na difusão e preservação da cultura (representada nos casos concretos sobretudo pelos usuários), e o autor.

As compensações atribuídas ao autor, e que significam os seus direitos exclusivos em relação à obra, sofrem restrições, toda vez que o interesse da coletividade é de tal modo urgente e superior que não permitiria uma composição da forma habitual.

Isto se compreende, não só porque a proteção se dirige à obra, e não ao autor, como pensavam muitos doutrinadores, como também, porque o autor ao criar nada mais fez que transformar, através de sua individualidade criativa, parte do acervo cultural que a coletividade preservou e transmitiu, adquirindo esta última direitos irrecusáveis em relação àquele patrimônio cultural, ao qual a obra do autor passará a pertencer, e de cuja existência dependeu a sua criação. ${ }^{3}$

Elementar é que a obra deva representar uma contribuição de alguma significância para o acervo cultural. A

3. Assim o Direito Autoral além de ter a sua natureza social (e que Direito não o tem?), seria também um direito natural, como o querem muitos juristas, na medida em que a obra autoral, pertencendo ao patrimônio cultural de um país, quiçá do mundo, tem na sua essência a ânsia de se ver preservada, divulgada, transmitida, interpretada, assimilada, e desenvolvida. Isto porque essa necessidade, absolutamente anterior a qualquer interferência legislativa, é um fato básico para a existência do próprio conceito de cultura. - Na própria natureza da cultura está a ânsia referida, e que leva ao estabelecimento de direitos especiais, para todos que a preservem, transmitam, divulguem; interpretem, assimilem e desenvolvam. É evidente, também, que nessa tarefa a coletividade antecede e sobrepuja o autor, daí a legitimidade irre- 
este último, o filtro da criatividade individual deve ter, ao assimilá-lo, conseguido obter certa mudança relevante para a arte, literatura ou ciência. Por isso não se protege o plágio.

Admirável é portanto pela sua clareza, inteligência e profundidade a lição precursora nesta matéria do Professor Antônio Chaves no sentido de que a proteção é da obra e não do autor ${ }^{4}$. Lição essa, que materializou-se no Projeto de Código de Direitos do Autor e Direitos Conexos, de sua co-autoria, e que preceitua:

"A criação de uma obra intelectual, seja qual for seu gênero, forma de expressão e destinação, confere ao autor os direitos morais e pecuniários cuja defesa as normas de ordem pública deste Código asseguram".

Os Direitos Autorais envolvem atributos de ordem moral $^{5}$ e de ordem pecuniária. São esses últimos os que mais nos interessam.

cusável das restrições que aquela, no interesse da própria cultura, impõe ao direito atribuído aos criadores. - Mais evidentes ainda se tornam estas noções quando se verifica que findo um lapso de tempo razoável, em que se acredita haver compensado o autor, volta a obra ao patrinônio da coletividade, configurado no domínio público.

4. A. Chaves - O Projeto de Código de Direito do Autor e Direitos Conexos, Revista da Faculdade de Direito, São Paulo 66, 115-117, 1971.

5. Sobre eles, embora fujam ao interesse imediato desta exposição, permaneceram ainda esclarecedores os conceitos emitidos por PoULLET: "C'est en réalité, le droit, pour l'écrivain et l'artiste, de créer et de faire respecter sa pensée. le droit de défendre l'oeuvre contre lesi dénaturations que quiconque, ... lui ferait subir..." (PouILLET, Euğ̀̀NE - Traité théorique et pratique de la propriété littéraire et artistique et $d u$ droit de représentation. 3. ed. refondue par Georges Maillard et Charlez Claro, Paris, Marchal et Billard, 1908, cap. VII, p. 256, 259). - Elucidativa é ainda a definição de GENY que encontramos na mag.nífica tese de PhILAdELPHo AZEvEDo, “c'est un droit d'ordre principalement moral ou personnel, en vertu duquel l'écrivain dispose exclusivement de sa pensée pour l'informer à sa guise, puis la retenir ou la communiquer au public, ou bien, la lui ayant offerte, la reprendre, la modifier ou l'anéantir, soit qu'il agisse lui même dans un de ces sens, soit qu'il empêche les autre d'agir à l'encontre de ses intentions propres" Ou ainda a que professou GEORGeS BRY e que encontramos na 
Os atributos pecuniários são alienáveis, porque seu exercício pode ser cedido a terceiros (assim um autor cede ao editor o direito de reproduzir graficamente a sua obra); são temporários, porque esta autorização não é perpétua e sofre limitações no tempo; são divisíveis porque se exige uma autorização para cada uma das formas de utilização relacionadas, (assim, quem autoriza uma gravação em disco não está permitindo a execução pública da obra); e são relativos, renunciáveis e prescritíveis, ao contrário dos atributos de ordem moral, que são perpétuos, irrenunciáveis e imprescritíveis.

Os atributos pecuniários permitem utilização sob forma corpórea e sob forma incorpórea.

No primeiro caso, sob forma corpórea, temos os Direitos de Exposição, Exibição, Sequela, Distribuição, Reprodução etc.

No segundo caso, sob forma incorpórea, temos os Direitos de Recitação Pública, Radiodifusão, Execução e Representação, Direitos de comunicar e fixar a execuçâo e representação, e outros ${ }^{6}$.

É nosso objetivo atual o Direito de Execução. Ele se define como a divulgação sonora, ou então, mais amplamente, como a reprodução acústica de uma obra musical. $O$ conceito jurídico-autoral de execução, se cinge portanto às criações de natureza musical.

Em sua reprodução acústica, as obras dramáticas são representadas, as poéticas recitadas, e as musicais são executadas.

\footnotetext{
mesma tese: “... o conjunto de faculdades a vantagens que tendem a salvaguarda da personalidade do autor, a fazer respeitar sua inspiração, suas idéias, seu nome, a integralidade de sua obra..." (Direito Moral do Escritor, Rio de Janeiro, Alba, 1930, p. 38).

6. Seguimos nesta divisão de utilização corpórea e incorpórea a orientação e enunciados adotados no "Projeto de Código. " antes citado.
} 
A vontade e a ação material do indivíduo executante, são dirigidas na execução no sentido de realizar a reprodução sonora.

A execução pode ser direta ou indireta. É direta quando se dirige do executante diretamente ao ouvinte. $\mathrm{E}$ é, por conseguinte, indireta, quando o processo se cinde em duas etapas distintas: na primeira, o executante, ou fixa sua execução em um suporte material (como discos, fitas, tapes etc.) ou então realiza a reprodução para que um urganismo de radiodifusão a capte. Na segunda etapa, a execução fixada ou captada, é então, comunicada ao ouvinte. Assim, é execução direta aquela que uma orquestra faz em um clube diretamente aos sócios, e é indireta, tanto aquela em que a audição se efetua através de discos, fitas, etc., como a que se realiza através de um rádio ou televisão.

A execução pode igualmente ser pública ou privada.

Privada ela é, quando restrita ao círculo familiar, à esfera intima do indivíduo.

Pública ela se torna quando se efetua a comunicação da obra a uma pluralidade de pessoas que não esteja unida pelos estreitos laços da intimidade e do parentesco.

Segundo Pontes DE Miranda, haveria que distinguir ainda, entre audição retribuída e execução retribuída ${ }^{7}$

Execução retribuída seria aquela em que o executante recebesse remuneração pelo seu trabalho, muito embora os ouvintes pudessem estar assistindo gratuitamente. $E$ o caso do pai que aluga um clube e paga aos músicos para a festa de aniversário de seu filho.

Audição retribuída por outro lado, seria aquela em que as pessoas que assistissem devessem pagar ao executante ou a terceiro para poder presenciar à execução (é o caso de pessoas que compram ingressos para um baile).

Podemos adiantar, no entanto, que a distinção, por si só, não tem no estado atual do nosso Direito, a importância

7. Miranda, Pontes De; Tratado de Direito Privado, $2 .^{\mathrm{a}}$ ed., Rio de Janeiro, Borsoi, 1956, v. 16, Cap. viII, p. 177-79. 
que se the quis atribuir. Sozinha, sem o critério da publicidade ela é inútil.

No primeiro caso, na execução retribuída, é uma pessoa, o pai, que se substitui aos ouvintes na obrigação de pagar ao executante. No segundo caso, na audição retribuída, é o próprio ouvinte quem paga, comprando os ingressos.

Quando a audição fosse retribuída mas o executante não recebesse remuneração, como por exemplo num espetáculo de beneficência, não haveria também interesse na distinção. Porque segundo o estabelecido pelo Código Civil Brasileiro em seu artigo 657: "Publicada e exposta a venda uma obra teatral ou musical, entende-se anuir o autor a que se represente ou execute, onde quer que sua audição não for retribuída".

A pessoa que paga um espetáculo de beneficiência está visivelmente retribuindo, quando não ao organizador, pelo menos ao beneficiário.

Os conceitos tinham que ser referidos, apesar da nossa observação a respeito, devido sua importância para o manuseio da espécie que estudamos.

Antes de evoluirmos na sua análise, queremos abrir um parênteses para esclarecer o que sejam os Direitos Conexos ao Direito de Autor.

A significância deles deflui para nós, da obrigação que tem os clubes de pagar pelos Direitos Conexos, quando haja execução indireta de obras musicais.

Se a realização de uma obra faz derivar para seu autor direitos especiais porque o Estado quer amparar a cultura, todos aqueles intermediários (como por exemplo cantores, músicos etc.) que tenham atuação indispensável no processo de comunicar a obra ao público e que assim acrescentem à criação do autor, elementos pessoais e especiais, seja de ordem intelectual técnica ou mecânica, é justo que esses intermediários, sejam também merecedores de Direitos específicos conexos àquele do autor. A sua atividade se tornou imprescindível à divulgação da cultura. 
No Direito Brasileiro eles foram reconhecidos pela promulgação da Convenção de Roma através do Decreto 57.125 de 1965 e pela publicação da lei 4.944 e sua regulamentação pelo Decreto 61.123, ambos de 1966.

Dizíamos que o Código Civil exigiu para que houvesse exceção ao Direito de Autor de Execução de Obras Musicais além da ocorrência da não retribuição da audição, a condição de que a obra houvesse sido publicada e exposta à venda.

Assim a obra inédita ficava sujeita ao consentimento do autor, mesmo quando a sua audição não fosse retribuída.

Em 1924 o Decreto 4.790 no artigo $2 .^{\circ}$, acrescentava, que nos espetáculos públicos quando houvesse pagamento de entrada, era necessária a autorização do autor, para cada vez que se pretendesse executar composições musicais.

E em 1928, os Decretos 5.492 e 18.527, regulando as empresas de diversões e locação de serviços teatrais, deixavam disposto, respectivamente nos artigos 26 e 47, que as composições musicais executadas ou transmitidas pela radiotelefonia, com o intuito de lucro, em reuniões públicas ficavam sujeitas ao consentimento do autor. E o parágrafo único presumia que a retribuição paga a músicos, executantes ou transmitentes representava intuito de lucro.

Consagravam-se aí os dois critérios que viriam a nortear definitivamente a matéria.

Notaram os juristas que a audição seria retribuída, não apenas, naquelas ocasióes em que houvesse o pagamento direto e evidente por parte do ouvinte, mas também naqueles outros casos em que esta remuneração se processasse de maneira menos perceptível.

Para esclarecer estas hipóteses pouco nítidas de retribuição, mas em que ela inegavelmente ocorria, elegeu-se o intuito de lucro como critério, amparado pelo da publicidade da reunião. 
Intuito de lucro direto, ou da audição diretamente retribuída, ocorreria nos casos em que se desse a cobrança de ingressos ou exigência de consumação mínima, por exemplo.

Já o intuito de lucro indireto, ou audição indiretamente retribuída se caracterizaria em seu sentido amplo atual, como o esclarece o Anteprojeto do Desembargador Milton Sebastião Barbosa, "pela cobrança de taxas ou mensalidades, pelo recebimento de subvenções, aluguel de salóes para qualquer espetáculo ou festividade, a exploração publicitária em geral, a existência de qualquer finalidade econômica ou comercial, o pagamento de remuneração por qualquer forma, a artistas, intérpretes, músicos, executantes ou semelhantes, inclusive, a qualquer outra pessoa no local onde a obra é utilizada"s.

Assim o intuito de lucro não se resumiria meramente na intenção de usufruir vantagens com o uso da obra, mas alcançaria também aquelas hipóteses em que objetivamente pela sua utilização, resultassem benefícios para o usuário.

Lucro quer dizer "Utilidade, ganho, interesse, proveito, produto livre de despesas".

"A análise econômica contemporânea", segundo HeNri Gurton, professor de Economia Política da Universidade de Paris, "não considera lucro senão o excedente. . Há lucro" diz ele "apenas existe um excedente, uma vez pagos todos gastos gerais, todas as matérias primas, e todos os serviços produtivos, assegurados o renovamento das partes envelhecidas da empresa e a possibilidade de prevenir os imprevistos do futuro"?.

Embora de ordem nitidamente econômica, a palavra em sua presente acepção jurídico-autoral como na que lhe deu o uso popular, significa mais amplamente um benefício

8. Diário Oficial, Seção I, Parte I, Supl. ao n. 113 , art. 79,16 de junho de 1967, p. 19.

9. Gutton, Henri, Economia Política, 2.a ed., Rio de Janeiro, Fundo de Cultura, 1961, v. 4, p. 60-1. 
genérico, de diversas categorias desvinculando-se do seu aspecto econômico inicial.

Um clube social é uma pessoa jurídica de direito privado, constituída para o proveito exclusivo de seus associados. Não visa o lucro econômico. Interessa-se em cobrar pelos serviços que presta para pagar suas despesas e, quando muito, para reinvestir em bens e serviços que sirvam à comodidade ao lazer de seus sócios. Só são remunerados os funcionários, nunca os membros do quadro social.

Contudo, a execução de músicas em clubes, porque visa o proveito de seus associados, é uma audição indiretamente retribuída por ele.

O lucro que se tem em vista é o bem estar e o divertimento. Para obtê-los o sócio paga a mensalidade que nada mais é que uma retribuição pelas comodidades que goza.

Não foi pacífica, porém, a evolução do conceito de execução musical em clubes e sociedades recreativas. Para que vestisse o antes apertado conceito de audição retribuída, precisou haver uma lenta progressão jurisprudencial, doutrinária e legislativa. E sobretudo precisou-se ampará-lo pelo critério da publicidade, que, por si só, já deveria ter sido suficiente.

Para compreender essa transformação é preciso sobretudo perceber que sendo a música o elemento básico e essencial, sem o que não se pode realizar qualquer festa, haile ou reunião dançante, revoltava aos autores e comovia os juristas o fato de que, embora pagando funcionários, decoração, músicos, operários, lavanderia, bebidas e outros fornecedores ${ }^{10}$, os clubes escorados pelas imprecisões e lacunas da lei, se esquivassem ao pagamento dos Direitos Autorais, que afinal de contas são o ganha pão dos autores. como se uma fábrica se recusasse a pagar pela matéria prima que vai industrializar.

10. Ver a este respeito precisa argumentação do Prof. ANTônio Chaves, in op. cit., p. 127. 
Opondo-se a estas mutações, os clubes embora isolados, lutavam resolutamente pelos seus interesses.

Assim distinguiu-se entre o conceito de espetáculo público e o de espetáculo privado, para, incluindo os clubes na última categoria, isentá-los do pagamento dos Direitos Autorais. De vez que suas reuniões seriam coletivas mas não publicas, porque restritas aos sócios e convidados ${ }^{11}$.

Porém, inúmeros julgados, e, mais ainda, o Decreto 20.493 de 1946 regulamentando os Serviços de Censura de Diversões Públicas, assemelhou expressamente, no artigo 88, os lugares de reuniões públicas aos de reuniões colelivas, eliminando por conseguinte a diferença e exigindo a autorização do autor, para a aprovação de programas de audições musicais nesses lugares. Outras e diversas decisões judiciais se sucederam, contudo, em vários tribunais do país, notadamente no do Estado do Paraná, afirmando o caráter privado nas reunióes em clubes ${ }^{12}$, e a gratuidade das audiçốes.

Procurou-se também fixar que as decisões contrárias ao interesse dos clubes apoiavam-se em diplomas legais que dispunham somente acerca de empresas de diversões e locação de serviços teatrais, sujeitas ao regime das sociedades comerciais e que, por isso, não poderiam ter sido aplicados aos clubes que são sociedades civis sem finalidade lucrativa ${ }^{13}$.

11. Duval, Hermano, Violação dos Direitos Autoriais, Rio de Janeiro, Borsoi, 1968, Título II, Cap. I, n. 95, p. 227.

12. Revista dos Tribunais do Estado de São Paulo, v. 392, p. 356, 1968 , v. 345 , p. 487 , v. 350 , p. 540,1964 , v. 228 , p. 548 , v. 149 , p. 141 , v. 164, p. 731 , v. 253 , p. 609 , v. 384 , p. $550-$ Arquivo Judiciário, v. 108 , p. 218 , v. 116 , p. 412 , v. 113, p. 62 , v. 105 , fasc. 2, p. 291, fev. 1953 - Ementário Forense, ano 10, n. 115, 1958, ano 4, n. 66, 1954 - D. J., p. 322 apenso ao n. 209, maio 1961.

13. Hermano Duval, op. cit., n. 97, p. 231-32 - Em contrário consulte-se: Revista dos Tribunais de São Paulo, v. 339, p. 298, v. 328, p. 719 , v. 262 , p. 145 , ago. 1957 , v. 188 , p. 476 , v. 194 , p. 382 - Jurisprudência, súmula 353, p. 350, 1967. - Consultar também 
Em meio a esta efervescência jurisprudencial também se pronunciavam continuamente os tribunais, e notadamente o Supremo Tribunal Federal, interpretando a lei em sentido oposto àquelas entidades, sendo marcante o importantíssimo e sempre citado relatório do Ministro Amarílio Benjamim no agravo de petição ao mandado de segurança 17.173 , em que afirmou o caráter público e o intuito de lucro existente nas reuniões em clubes, e a equivalência desses últimos a verdadeiras empresas de recreação ${ }^{14}$.

Houve ainda quem tentasse eximir as mencionadas associações da obrigação de pagar a execução indireta, seja através de discos, seja pela radiodifusão, sob o argumento de que a cessão do Direito de Reprodução num caso, e o de Execução pago pelas empresas de Radiodifusão no outro, já remunerava suficientemente o autor ${ }^{15}$. Mas a tese esquecia o caráter eminentemente divisível dos atributos pecuniários, e não poderia de forma alguma ser acolhida, como não o foi.

Atualmente temos diante de nós uma jurisprudência firmada no Supremo Tribunal Federal reconhecendo a obrigação dos clubes pagarem aos autores; contudo nas instâncias inferiores continuam-se a encontrar, vez por outra, decisões opostas, mas que, ao final, são necessariamente reformuladas, toda vez que alcançam o órgão Máximo do nosso Poder Judiciário.

Finalmente o projeto da co-autoria do professor ANTôNio Chaves espantou todas as incertezas, pela adoção definitiva de um critério de superior clareza que é o da publicidade. Assim o artigo 27 dispõe que "todas as execuções ou representações públicas ainda que sem finalidade lucra-

extensa jurisprudência relacionada no parecer Direito de Autor Discos Gramofônicos - Execução não autorizada de Obras Musicais, de A. Chaves, in Rev. Trib., v. p. 42.

14. Censura Federal, Brasília, Carlos Rodrigues Editôra, 1971, p. 282 .

15. Hermano Duval, op. cit., Título VII, Cap. II, n. 160, p. $420-21$. 
tiva, direta ou indireta... “dependerão do pagamento prévio da retribuição $0^{16}$.

Srs., havendo sido convidado pelos organizadores desta Convenção para proferir esta palestra, poderia parecer a alguém. que eu devesse negar vivamente o Direito dos Autores. Essa atitude, aparentemente fácil, quem sabe (?), poderia me lograr posição mais simpática perante os senhores Convencionais.

Entretanto as pessoas aqui presentes não são ingênuas. Todas, de uma forma ou de outra, já tiveram que se defrontar com a dúvida em pagar ou não os Diretios Autorais. A experiência prática já as acautelou. As batalhas judiciais de que participaram ou tiveram notícia, são suas melhores. conselheiras.

$\mathrm{Na}$ absoluta maioria dos países civilizados os clubes pagam direitos autorais.

Desonesto seria eu, se viesse levantar falsas esperanças, animando-os a atitudes, que ao final, só redundariam nas mais funestas conseqüências jurídicas.

O advogado no mundo contemporâneo, é, antes de tudo, um consultor, que previne as possiveis demandas, evitando os processos judiciais inúteis, lentos e dispendiosos.

Os autores têm hoje os seus direitos, alicerçados processualmente em meios eficazes para reprimir as violações de que sejam vítimas.

E a tutela civil e penal se já é suficiente como está, caminhou nos projetos elaborados, para uma repressão mais cerrada, e para uma ameaça mais sensível, que realmente alarme, assuste e afugente os possíveis violadores das normas jurídico-autorais.

O artigo 184 do Código Penal vigente estabelece que é crime "violar Direito de Autor de obra artística, literária e científica". Podendo esse ilícito originar ação penal mediante queixa do ofendido e subseqüente condenação em pena de detenção de três meses a um ano.

16. ANTônio Chaves, ox. cit., p. 127. 
A Lei Processual Civil assegura o Interdito Proibitório, como medida preventiva, contra a ameaça de turbação à posse dos Direitos Autorais.

Tanto o Código de Processo Civil como o de Processo Penal permitem a utilização da ação de busca e apreensão, como medida cautelar de natureza coercitiva, destinada a colher elementos probatórios da ocorrência de ilícitos. (Discos, fitas, tapes podem ser aprendidos, e os aparelhos de reprodução lacrados por determinação judicial).

Pode ainda ser requerida a interdição do espetáculo e interposta ação de perdas e danos no fôro civil, bem como a ação cominatória para prestação de fato ou abstenção de ato, com a conseqüente cominação de multa pecuniária pela violação do preceito.

Não foi portanto, desavisadamente, que agimos, quando, continuada e energicamente, advertimos de que a violação dos Direitos Autorais repugna a consciência jurídica. Sabíamos dos riscos a que os equívocos poderiam sujeitá-los. Por isso talvez, tenhamos sido exaustivos e um tanto detalhistas. Visamos à compreensão didática, e à apreensão lógica pelos senhores dos fundamentos da matéria que estudamos.

Agora, contudo, não menos energicamente desfraldo o estandarte dos seus interesses, e conclamo-os a juntos, nesta Convenção, analizarmos e encontrarmos soluções, atitudes e medidas comuns, para aquele âmbito de situações em que os clubes podem, e precisam fazer valer os seus direitos.

Trouxe-lhes algumas sugestões.

Constantemente, ouço Diretores de Clubes Sociais que reclamam, justificadamente, quando manifestam sua apreensão diante do modo arbitrário com que, algumas vezes, os representantes dos autores fixam os preços pelos Direitos Autorizados.

Os clubes precisam de uma previsão orçamentária antecipada das suas despesas. Mas são surpreendidos, reiteradamente, pela solicitação de remunerações desproporcionadas, por parte de alguns representantes dos autores. 
Quantos clubes não tem evitado realizar bailes de carnaval e outras festividades especiais, porque não podem fazer face aos gastos onerosos com os Direitos Autorais.

Costuma-se replicar que o porcentual não é exagerado, quando considerado no conjunto das demais despesas. Mas, se assim fosse, por que iriam estas entidades resignar-se a não mais proporcionar esse bem estar aos seus sócios, se é precisamente esta a finalidade que anima a sua existència jurídico-civil.

Não sou eu quem abstratamente formula estas preocupações, é a lamentação dos clubes que chega continuadamente aos meus ouvidos.

O Anteprojeto do Desembargador MiLton Sebastião BARBosa havia criado um sistema de tabelas mínimas bienais obrigatórias, fixadas antecipadamente para a cobrança dos Direitos Autorais.

Foi porém abandonado, em favor de outro inegávelmente superior, em muitos aspectos, ao que o antecedeu. As disposições quanto a tabelas mínimas, parecem ter sido suprimidas, porque suprimido foi o sistema de arrecadação centralizado e estatal antes estabelecido.

Se por considerações jurídicas e práticas irrecusáveis as alterações foram necessárias, os motivos que levaram à criação daquelas limitações ao Direito do Autor ainda permanecem vivos. $\mathrm{E}$ os nossos juristas certamente não os terão esquecido.

Cabe aos clubes, agora, colaborar para que seja encontrada a maneira pela qual, dentro da nova orientação adotada, seja possível resguardar os seus justificados interesses. Cabe a eles unificadamente agir para que sôe mais forte o seu murmúrio, para que se constitua num grito que emocione a sensibilidade jurídica da Nação.

Os autores atualmente podem cobrar o que quiserem. A jurisprudência lhes atribui o Direito de fixar como queiram o preço, em autorizações antecipadas. 
Diz-se que os clubes podem, se quiserem, deixar de utilizar músicas em suas sedes. Mas como, se ela é um elemento indispensável ao lazer contemporâneo?

Será que sob o exercício de um direito legítimo, vai se abrigar o verdadeiro abuso, em que se traduz em algumas ocasiões, a fixação e cobrança arbitrária por parte de alguns representantes dos autores do preço pelos Direitos Autorais?

No decorrer desta Convenção, na análise de outras disciplinas, os senhores terão inúmeras oportunidades de verificar as vantagens de se reunir em uma organização. As empresas enfrentam melhor as realidades econômicas do mundo atual, quando estão juntas.

Do ponto de vista da matéria que estudamos, também.

Por que não se criar um serviço jurídico único $\mathrm{e}$ centralizado, que os assessores nos problemas de Direito Autoral. Serviço esse, que firme com os autores os contratos de utilização, obtendo vantagens e redução dos preços. (Como por exemplo ocorre na Alemanha, aonde os contratos firmados por associações de entidades privadas, obtêm até $20 \%$ de desconto) ${ }^{17}$.

Unidos os clubes vão pedir, sim; mas saber também exigir quando se fizer necessário.

Por que não baratear os custos da manutenção de um quase sempre dispendioso mecanismo de assistência jurídica isolada e individual? Por que não reforçarem mútuamente, uns a posição dos outros?

Por quê não implantar um serviço centralizado com sistema de classificação e arquivamento que lembre os clubes de suas obrigações, e oriente-os quanto a seus compromissos econômicos, até mesmo pagando por eles?

Sim! Se os autores têm sociedades para arrecadar, os clubes também podem ter entidade para a realização con-

17. Chaves, Antônio, A arrecadação do Direito de Autor na Europa, in: Revista da Faculdade de Direito da Universidade de São Paulo, 1971, v. 66, p. 413-14. 
junta do pagamento, e por que não para exigir critérios mais justos na cobrança?

Quem desconhece que muitas vezes um clube de patrimônio vultoso quase não realiza festas e faz pequena utilização da matéria prima musical, embora pague alto pelos Direitos Autorais? Ao passo que um clube mais morlesto, por estar auferindo a maioria das suas rendas pelos serviços que presta durante os bailes e reuniões dançantes, paga pouco pelos mesmos Direitos.

Por quê não se exigir um critério que constate a utilização real da música, para orientar a cobrança dos Direitos Autorais. Talvez estabelecendo um percentual fixo sob determinado valor (como por exemplo "tantos por cento" sobre a arrecadação do clube). De tal forma que se possa antecipar os gastos e evitar desequilíbrios no orçamento geral.

Por quê, ao menos, não adotar um sistema comum, embora exercido individualmente, para a quitação dos Direitos Autorais (como a utilização de "carnets" bancários, sem prejuizo da aprovação dos programas pela censura).

Barateando o custo para os senhores, estarão diminuindo também os gastos da onerosa máquina de arrecadação e fiscalização que os autores mantêm. Beneficiando-os os senhores podem exigir a redução das remunerações que pagam.

Estou convicto de que os representantes dos autores se aqui compareceram é porque estão interessados também em encontrar formas de entendimento comum.

$\mathrm{E}$ além disso, por quê não aproveitar a ocasião, e redigir ao sr. Ministro da Justiça um documento que se destine a receber a assinatura de todos os dirigentes de clubes no Brasil, aprovando as recomendações desta Convenção acerca dos Direitos Autorais, solicitando a S. Excelência que sejam tomadas em consideração na redação final do Projeto de Código.

Por quê não se pugnar pela criação de uma Comissão ou órgão especial composto de representantes dos autores, 
dos usuários e elementos mediadores de nomeação do governo, que arbitre e fixe os critérios e percentuais para cobrança de direitos de execução musical, procurando resolver em caráter preliminar os litígios existentes, sem prejuízo das demais medidas judiciais facultadas legalmente aos interessados para defesa de seus direitos

São 23.000 os clubes sociais no Brasil, são portanto 23.000 comunidades cujos direitos, interesses, e reinvindicações não devem ser descuidados.

Todas estas proposições, que apresentamos, foram relacionadas na constituição de um documento, que se propõe ao exame, análise e crítica desta Convenção, admitindo sugestões e reformulações.

Ofereço-o como ponto de partida para os trabalhos da Comissão específica.

Senhores, somos aqui apenas algumas centenas de entidades, uma reduzida quantidade face ao total das congêneres existentes. Mas é sempre do desassombro de uns poucos, que comandam e têm a iniciativa dos fatos, que resulta o benefício geral.

Assim tem sido, até mesmo com a inauguração das Nações que, como o Brasil, hoje ostentam com orgulho a sua independência.

Os clubes, tenho a certeza, não permanecerão passivos diante dessas realidades inadiáveis. 